\title{
POBREZA DA EXPERIÊNCIA E MIMESIS NA FORMAÇÃO INFANTIL: RELEXÕES A PARTIR DE ALGUNS ENSAIOS DE WALTER BENJAMIN
}

\author{
Rodrigo Sousa Fialho ${ }^{1}$ \\ Eduardo Jorge Oliveira Triandopolis ${ }^{2}$
}

\begin{abstract}
RESUMO
$\mathrm{Na}$ modernidade, o desenvolvimento da técnica desencadeou uma série de consequências nefastas, tais como o retraimento da capacidade de transmitir experiências. Mas na perda da experiência havida neste contexto, eleva-se a importância da mímesis na educação infantil, não apenas enquanto mera imitação, mas como maneira da criança conhecer a si e o mundo. Nos ensaios do filósofo Walter Benjamin, encontramos importantes aspectos da filosofia da educação relacionados à imitação e à repetição, características lúdicas de apreensão do mundo, onde a criança cria seu pequeno mundo no interior do mundo. Estas características valorizam o que os adultos costumam ignorar e estabelecem, na diversidade dos materiais apreendidos, novas relações em um universo próprio.
\end{abstract}

Palavras-chave: Experiência. Narrativa. Mímesis. Criança. Formação.

\section{POORNESS AND EXPERIENCE, MIMESIS IN CHILD EDUCATION: REFLEXTIONS FROM SOME TRIALS OF WALTER BENJAMIN}

\begin{abstract}
In modernity, the development of technology has triggered a number of adverse consequences, such as the withdrawal of the ability to transmit experiences. But the loss of experience regarded in this context, rises the importance of mimesis in early childhood education, not only as mere imitation, but the child as a way to know yourself and the world. In tests of the philosopher Walter Benjamin, we found important aspects of educational philosophy related to imitation and repetition, entertaining features of apprehension of the world, where the child creates his own little world within the world. These features value what adults usually ignore and lay in the diversity of materials seized, new relationships in a world of its own.
\end{abstract}

Keywords: Experience. Narrative. Mimesis. Child. Training.

\section{Introdução}

\footnotetext{
${ }^{1}$ Mestrando em Filosofia na Universidade Estadual do Ceará e Professor Substituto da Universidade Estadual Vale do Acaraú. fialhorodrigo@hotmail.com

${ }_{2}^{2}$ Doutor em Filosofia, Pós-doutor em Antropologia histórica pela Universidade Livre de Berlim e Professor da Universidade Estadual do Ceará. epolis@uol.com.br
} 
Abordar as características do universo infantil nos ensaios de Walter Benjamin encontrados na obra Reflexões sobre o Brinquedo, a Criança e a Educação, requer uma reflexão acerca de alguns conceitos: experiência, modernidade, rememoração, narrativa e mimesis.

Nos ensaios da obra citada, Benjamin fomenta o debate acerca dos axiomas que fundamentam a formação infantil no contexto da sociedade burguesa e apresenta a vida infantil vinculada a sua leitura da história que aponta para um resgate da tradição e da memória suprimida no desenrolar do processo de consolidação da modernidade. Ao empreender a busca pela compreensão do universo infantil, o filósofo indaga acerca das formas de educar na modernidade, e promove, assim, uma reformulação teórica condizente com uma nova práxis política.

A visão de mundo da criança é erigida a partir de sua própria sensibilidade. Para Benjamin, não há infância desconectada do social. "O mundo perceptivo da criança se enraíza e, ao mesmo tempo, se confronta com o mundo histórico." (SCHLESENER, 2011, p. 130). No processo de adaptação às exigências do universo adulto, a criança é capaz de recepcionar as semelhanças sensíveis e de apreender o mundo. Com efeito, a experiência infantil da mimesis, do lúdico, do brinquedo, não só se distingue como se contrapõe à experiência da vida adulta, já plenamente integrada aos ditames da modernidade. Porém, antes de examinarmos o universo infantil e a importância da imitação na formação da criança, abordaremos o conceito de experiência e a pobreza desta no contexto da sociedade moderna.

\section{Empobrecimento da Experiência}

A compreensão do empobrecimento da experiência para Benjamin dá-se no cenário da modernidade e está relacionada ao esmaecimento da capacidade de narrar (contar histórias), o que denota a perda de referências coletivas. Aqui, nos propomos a apresentar a ideia benjaminiana de experiência, cuja recuperação histórica implica na busca de caminhos que conduzam ao resgate da memória, enquanto elo entre passado e presente.

Experiência (Erfahrung) e vivência (Erlebnis) são conceitos distintos com os quais Benjamin expressa características da modernidade e enfatiza a inexistência de vínculo com o passado e a decadência espiritual. O modo de 
vida e de produção da sociedade moderna, assessorada pelo aparato mecânico, é, para ele, a causa do empobrecimento da experiência, o que ocasionou a submersão do homem na dimensão individualizante da vida.

$O$ processo de edificação da sociedade moderna teve reflexo na educação. Em uma série de ensaios publicados entre 1913 e 1916, o filósofo alemão critica o sistema de ensino de sua pátria. $\mathrm{Na}$ mira da crítica benjaminiana encontra-se 0 ensino reduzido à profissionalização, principalmente na era bismarckeana, e os interesses escusos e utilitários a serviço da pesquisa científica regulamentada pelo Estado. Para Benjamin, a função do pensamento e da universidade é diluída por tais relações. O compromisso do estudante com o pensamento crítico e com mudanças na sociedade não condiz com o assistencialismo estatal.

A moderna sociedade, ao não reconhecer a velhice, encontra dificuldade de identificar também a juventude, precisamente por não dar o devido reconhecimento à decrepitude humana dada no tempo. Benjamin considera que o envelhecimento requer a consciência de que a vida humana está ligada ao passado e à tradição. Compreender o futuro e o passado no presente é a condição para uma autêntica vida de estudos e de ensino. Em "A vida dos estudantes" afirma o filósofo: É necessário desprender "o vindouro de sua forma desfigurada, reconhecendo-o no presente". (BENJAMIN, 2002, p. 47). O lamento da perda de algo grandioso possibilita a renovação da vida: "Apenas a nostalgia confessada por uma infância bela e uma juventude digna é a condição do criar". (BENJAMIN, 2002, p. 45-46).

No ensaio intitulado Experiência de 1913, Benjamin apresenta a vida moderna como uma somatória de vivências subjetivas, isto é, uma vida fragmentada. Aqui visualiza-se claramente a distinção entre os conceitos de experiência (Erfahrung) e vivência (Erlebnis). Enquanto o primeiro conceito faz referência a uma coletividade, o segundo aponta, como dissemos acima, para uma vida fragmentada. A projeção da imagem do adulto moderno: "... isso experimentaram eles, a falta de sentido da vida..." (BENJAMIN, 2002, p. 22) é expressão de uma temporalidade que perdeu o elo com a tradição.

A falta de comunicação entre gerações e a perda do elo do presente com a tradição, é a causa da mudez, apontada por Benjamin como característica da sociedade moderna. A experiência da vida adulta é marcada 
pela inexpressividade e impenetrabilidade que apontam para a desilusão e a desesperança que assolam o mundo. Para Benjamin, o adulto moderno é apegado aos dogmas erigidos a partir da vazia experiência que o caracteriza. Valendo-se de tais dogmas, o adulto impõe sua autoridade e vontade sobre os jovens. O discurso adulto fundamenta-se no acúmulo de conhecimentos oriundos da aplicação dos métodos indutivos e dedutivos que conduziram à crença de que a verdade é de fácil apreensão. A posse destes conhecimentos leva o adulto a definir a experiência juvenil como inútil e alucinatória. Para o adulto a verdade se apresenta na ordem vigente e, portanto, não há nada mais a conhecer. Diferente deste, o jovem acredita em uma verdade a se buscar e pela qual faz sentido viver. Numa sociedade com tais características, é possível entrever um modelo de formação que ignora por completo o novo e, sobretudo, a criatividade.

Ainda no ensaio Experiência, Benjamin alude à cultura filisteia que, segundo ele, constitui-se instrumento a serviço da manutenção do poder:

Nada é mais odioso ao filisteu do que os "sonhos da sua juventude". ( $E$, quase sempre, o sentimento é a camuflagem desse ódio.) Pois o que the surgia nesses sonhos era a voz do espírito, que também o convocou um dia, como a todos os homens. A juventude the é a lembrança eternamente incômodo dessa convocação. Por isso ele combate. O filisteu the fala daquela experiência cinzenta e prepotente, aconselha o jovem a zombar de si mesmo. Sobretudo porque "vivenciar" sem o espírito é confortável, embora funesto. ${ }^{3}$

Conforme Benjamin, para o filisteu, os anos que constituem a fase da juventude são quimeras. Após esta fase da vida, vem a maturidade, qualidade típica da fase adulta. Nesta, o indivíduo moderno já está plenamente integrado aos ditames do modo de produção característico de sua era. Assim, para o mencionado filósofo, a cultura filisteia funciona como um instrumento a serviço da estrutura econômica e social vigentes. O filisteu, portanto, é a imagem do adulto desprovido de sentido na vida. Tal imagem é antagônica à vida juvenil, caracterizada por aspirações e valores elevados, tais como a verdade, o bem, a fidelidade etc.

\footnotetext{
${ }^{3}$ BENJAMIN, 2002, p. 24
} 
Para o adulto moderno (adaptado à estrutura sócio-econômica vigente), educação resume-se à preparação para o trabalho profissional e à adaptação aos ditames da produtividade. Em outras palavras, a educação nega a dimensão onírica da existência na medida em que reduz o compromisso da função profissional a um exercício puramente operativo, deixando definhar todo o aspecto anímico e o elã vital da existência.

No ensaio Experiência e Pobreza, de 1933, Benjamin contrapõe a fragmentada experiência do homem moderno à experiência dos antigos, comunicáveis na forma de narrativas e provérbios. A perda da capacidade de narrar e o desenvolvimento do modo de produção capitalista fizeram emergir uma nova forma de miséria: a pobreza de experiências. A ruptura do elo entre passado e presente esvaziou de sentido a experiência, tornando-a incomunicável. A implementação da técnica no contexto de dominação política e econômica desfez o vínculo entre o homem do presente e a herança cultural, o que causou o atrofiamento da capacidade de transmitir experiências. Para Benjamin, é possível observar este fenômeno nos combatentes remanescentes da I Grande Guerra:

Talvez isso não seja tão estranho quanto parece. Na época, já se podia notar que os combatentes tinham voltado silenciosos do campo de batalha. Mais pobres de experiências comunicáveis, e não mais ricos. Os livros de guerra que inundaram o mercado literário nos dez anos seguintes não continham experiências transmissíveis de boca em boca. Não, o fenômeno não é estranho. Porque nunca houve experiências mais desmoralizadas que a experiência estratégica pela guerra de trincheiras, a experiência econômica pela inflação, a experiência do corpo pela fome, a experiência moral pelos governantes. ${ }^{4}$

Nesta passagem, Benjamim aponta para a mudez oriunda da incomunicabilidade de experiências, o que revela a profunda modificação estrutural da vida social. A experiência vivida não é transmissível mesmo quando carregada de verdade, pois, o que se impõe na sociedade que sofreu o impacto da técnica é a verdade desta última, isto é, das vivências, do trabalho

\footnotetext{
${ }^{4}$ BENJAMIN, 1987, p. $114-115$
} 
e do consumo. Delineiam-se aqui duas das principais características da modernidade: a pobreza da experiência e a incapacidade de transmiti-la.

A situação da pobreza da experiência está estreitamente relacionada à perda da capacidade de contar histórias, assunto que Benjamin desenvolve no ensaio intitulado O Narrador, de 1936. "A arte de narrar revela uma forma de pertencimento, de vínculo social e de experiência autêntica que se perdeu na modernidade". 5

Os ensaios Experiência e Pobreza e O Narrador trazem como questão de fundo, a abordagem benjaminiana do esmaecimento da identidade do homem no contexto da modernidade. Inserido num cenário em que vigoram novas relações políticas e econômicas e um presente desvinculado do passado, o homem torna-se incapaz de identificar suas próprias raízes.

A perda da capacidade de transmitir experiências por meio da narrativa dá-se concomitantemente ao advento do progresso das forças produtivas. $O$ romance é o sinal dessa perda, que só se tornou possível graças à invenção da imprensa e do isolamento do homem que, desprovido de referências coletivas, já não consegue mais transmitir suas inquietações mais profundas. A vivência da dimensão espaço-temporal fragmentada, própria do meio industrializado, impossibilitou o homem moderno de guardar na memória a experiência do passado. O resgate da experiência requer que se encontrem meios de se "reavivar a memória submersa no inconsciente". Tais meios são possibilitados pelo exercício da arte, na experiência infantil e no brinquedo, elementos fundamentais para a nossa reflexão acerca da educação.

\section{A importância da mimesis na educação da criança}

Expostas as convicções de Benjamin acerca da experiência e da perda desta no contexto da modernidade, devido ao esmaecimento da capacidade de narrar e do rompimento do elo temporal entre o homem moderno e a tradição (riquezas culturais acumuladas no inconsciente e passadas de geração a geração), passemos à abordagem da vida infantil, das diferenças desta para a vida adulta e ao tema da mímesis na formação da criança, na forma como é comentada por Benjamin em duas versões. Os ensaios A Doutrina das Semelhanças (Lehre vom Ähnlichen), e Sobre a Faculdade Mimética (Über

\footnotetext{
${ }^{5}$ SCHLESENER, 2011, p.132.
} 
das mimetische Vermögen) ${ }^{6}$ expõem a teoria dos sentidos onto e filogenéticos, que contribuem para 0 desenvolvimento infantil $e$ consequentemente para o aprendizado. ${ }^{7}$

A compreensão da experiência infantil passa pela crítica questionadora às práticas modernas de educação fundadas no individualismo e nos ditames do modo de produção industrial. Em Reflexões sobre o Brinquedo, a Criança e a Educação, Benjamin mostra com clareza aspectos da vida e do modo de percepção da criança, faz severas críticas aos hábitos da Alemanha dessa época e empreende uma leitura sui generis da história com o intuito de promover a retomada da memória e da tradição sufocadas pela modernidade. Detenhamo-nos no universo infantil e na diferença e incompatibilidade deste universo com o universo adulto, e na mímesis, como meio pelo qual, a criança identifica-se com as coisas e as conhece.

Conforme Benjamin, o que os adultos concebem como infância é algo diferente da realidade infantil. Mesmo a pedagogia não foi capaz de conceber a infância de maneira realista. Até o século XIX não se reconhecia a criança enquanto ser dotado de inteligência e, como reflexo disso, a educação consistia em transformá-la em adulto. Os pedagogos desenvolveram métodos e técnicas de acordo com os fundamentos teóricos predominantes de cada época. Durkheim, por exemplo, considerava a educação o meio de moldar a criança à forma adulta. Evidencia-se assim, o projeto de integrar a criança à comunidade, de modo a conferir identidade ao novo membro que cresce em seu interior. Para Benjamin, o individualismo impregnado na sociedade moderna é consequência da ideia de que a criança deve ser adequada ao modo de vida adulto. Com efeito, por não entender a percepção infantil, o adulto não compreende também o significado do brinquedo na vida da criança. O que, para o adulto, não passa de objetos irrelevantes e desprezíveis, para a criança, é meio de apreensão de si e do mundo.

Benjamin nota que a maneira da criança perceber as cores é o que concretiza a fantasia infantil, que é também o movimento da criança em direção ao torvelinho de nuances, em total conexão com seu desenvolvimento e alegria que a mantém em plena criação. Esta fantasia é produzida a partir da

\footnotetext{
${ }^{6}$ BENJAMIN, 1991, pp.204-210.

${ }^{7}$ BENJAMIN,1987, p. 99.
} 
sensibilidade da criança diante do mundo no qual vive e cuja contemplação se converte em um "sentimento criador". Por meio das coisas, as crianças adquirem o senso de orientação no mundo. A vida infantil concede novos sentidos à realidade, lançando questionamentos ao significado que as coisas adquiriram no contexto do modo de produção peculiar da modernidade. Ao brincar, a criança identifica-se aos objetos que a circundam, criando assim um mundo que é seu e no qual as coisas ganham sentido. Por meio da brincadeira a criança apropria-se do mundo, o que põe em evidência a relevância da mimesis na formação infantil. Benjamin observa, por exemplo, na criança, a capacidade de valorizar a brincadeira diante de um brinquedo "engendrado de acordo com as "bolorentas especulações dos pedagogos". ${ }^{8} \mathrm{O}$ brinquedo de origem fabril é superado pela brincadeira.

A brincadeira é a maneira da criança relacionar-se com o mundo. $O$ brincar aguça a criatividade infantil. Benjamin observa que à distância dos brinquedos em relação ao mundo adulto corresponde a proximidade destes em relação ao mundo da criança: quanto menos os brinquedos significam para o adulto, mais verdadeiros eles se tornam para as crianças, quer dizer, quanto mais próximos do universo adulto, mais distante o brinquedo fica da criança. Pela brincadeira - que consiste em imitação e repetição - a criança identifica-se com as coisas para então compreendê-las. Aqui, importa para Benjamin, a seguinte questão: qual a importância do aprendizado havido por meio da mimesis?

A resposta a esta questão é encontrada na experiência das coisas. Para o filósofo alemão, tal experiência é o jeito infantil de identificar-se com as coisas ao seu entorno e de habitar o mundo, sem preocupar-se em estabelecer limites ou violá-los, inventando, desse modo, uma forma peculiar de "pertencimento e temporalidade que resultam em novo conhecimento do mundo". 9

Benjamin destaca diferenças relevantes entre a experiência da vida infantil e da vida adulta. $O$ adulto tem na lógica e no controle os pressupostos da sua experiência; a repetição é para ele uma maneira de apropriação das experiências terríveis e desprovidas do sabor e do prazer típicos da experiência

\footnotetext{
${ }^{8}$ BENJAMIN, 1987, p. 18

${ }^{9}$ SCHLESENER, 2011, p. 133.
} 
infantil. Já para a criança, a brincadeira é uma fonte de prazer e meio pelo qual constrói sua subjetividade; a repetição e a imitação (próprias do brincar) é para ela um saborear as coisas e o modo pelo qual produz seu conhecimento do mundo. Sobre isso, escreve Benjamin em "Rua de mão única":

É que crianças são especialmente inclinadas a buscarem todo local de trabalho onde a atuação sobre as coisas se processa de maneira visível. Sentem-se irresistivelmente atraídas pelos detritos que se originam da construção, do trabalho no jardim ou em casa, da atividade do alfaiate ou do marceneiro. Nesses produtos residuais elas reconhecem o rosto que o mundo das coisas volta exatamente para elas, e somente para elas. Neles, estão menos empenhadas em reproduzir as obras dos adultos do que em estabelecer entre os mais diferentes materiais, através daquilo que criam em suas brincadeiras, uma relação nova e incoerente. Com isso as crianças formam o seu próprio mundo de coisas, um pequeno mundo inserido no grande. ${ }^{10}$

Para Benjamin, a faculdade mimética não se reduz à simples imitação, pois, na brincadeira, a mímesis é, na realidade, a maneira da criança conhecer o mundo. A criança ressignifica as coisas ao extraí-las do mundo adulto e transpô-las para o seu. Ao apontar para as diferenças entre os mundos adulto e infantil, Benjamin destaca os detritos como meio pelo qual a criança identifica-se com as coisas e as conhece. É apropriando-se a seu modo dos objetos - desprezados pelos adultos - que a criança apreende o mundo. Eis, portanto, a importância da imitação na formação infantil.

\section{Considerações finais}

As análises feitas a partir dos ensaios de Benjamin mostram os reflexos da modernidade na vida social e individual. Tais reflexos podem ser vistos claramente na distinção entre os conceitos de experiência, que nos remete a uma referência coletiva (ligada ao passado) e vivência, que denota a fragmentação característica da vida na sociedade moderna. A perda da experiência, fenômeno apontado como decorrente do impacto do desenvolvimento da técnica no interior da sociedade em que vigora o modo de produção industrial está diretamente relacionada ao enfraquecimento da

$\overline{{ }^{10} \text { (BENJAMIN, 2001, p. 103-104) }}$ 
capacidade de narrar, forma pela qual os antigos transmitiam suas experiências a seus descendentes. Até aí enfatizaram-se as consequências da modernidade na vida social e individual para, em seguida, refletirmos acerca da educação e da importância da imitação e repetição, próprias das brincadeiras, na formação da criança. Por meio da educação, os adultos e até, no decorrer da história, a pedagogia buscou integrar a criança ao modo de vida do adulto (mundo do trabalho e da produção), o que é apontado por Benjamin como incompreensão do universo infantil por parte do adulto. $\mathrm{Na}$ brincadeira, de maneira prazerosa, a criança questiona os pressupostos da sociedade moderna, conhecendo o mundo por meio da mímesis. Assim, "as características da experiência infantil se esboçam em vários fragmentos no sentido de mostrar uma forma original e concreta de tratar as coisas e conhecê-las". (SCHLESENER, 2011, p. 135).

\section{REFERÊNCIAS}

BENJAMIN, Walter. Obras escolhidas. Magia e técnica, arte e política. Ensaios sobre literatura e história da cultura. Trad. Sérgio Paulo Rouanet. Vol. 1. São Paulo: Brasiliense, 1987.

Reflexões sobre a criança, o brinquedo e a educação. Trad. Marcus Vinícius Mazzari. São Paulo: Duas Cidades; Editora 34, 2002.

Aufsätze Essays Vorträge - Gesammelte Schriften Band II-1, Frankfurt am Main: Suhrkamp Verlag, 1991.

CALLADO, Tereza de Castro, Walter Benjamin - a Experiência da Origem, Fortaleza: Eduece, 2006.

SCHLESENER, Anita Helena. Educação e infância em alguns escritos de Walter Benjamin. Revista Paidéia. Vol. 21. N. 48. Disponível em: <http://www.scielo.br/pdf/paideia/v21n48/a15v21n48.pdf>. Acesso em 11 nov. 2013.

GEBAUER/WULF, Mimese na cultura. Trad. Eduardo Triandopolis, São Paulo: AnaBlume, 2004. 